\section{A New Type of the Compound Eye}

IN entomology the real compound eye (excluding the agglomeratod eye) is considered to be provided with the hexagonal facet either in its outer or inner layer of the cornea. It is well known that the size of the facet is uniform in most of the compound eye of insects with some excoptional cases, such as the oyos of a certain Tabanid-fly and dragon-fly, and moth of Psilogramma increta. The first type of the eye is formed by two divided parts with large and mall facots, the second type of the eye has facets the size of which increases from ventrally to dorsally, and the third type of the eyo has small facets at the peripheral part and has larger facets the size of which increases toward the ceatre of the eye. I have found that the compound eye of a butterfly of Leptidea (Pieridae) has two kinds of deformed hexagonal facet which differ in the size intermingling together with an irregular arrangement in the whole surface of the eye as shown in Fig. 1.

The smaller facet has a diameter of nearly 60 per cent of that of the larger one. The internal structure of these smaller and larger facets corresponds to the outer facetal form of irregular hexagon as shown in Fig. 2.

The diameter of the cross-section of a unit of four corneagen cells of the smaller one is nearly 60 per cent of that of the larger one. This is also confirmed in their length (Fig. 3). It is certain that the ratio of the foregoing two smaller and larger parts of the eye is variable within a small range according to species and even within an individual of the same species. However, the compound eye of all species in the genus Leptidea ( $L$. duponcheli, $L$. morsei, $L$. sinapis, $L$. gigantea, etc.) shows the same type of irregularity as in the case of Leptidea amurensis of the

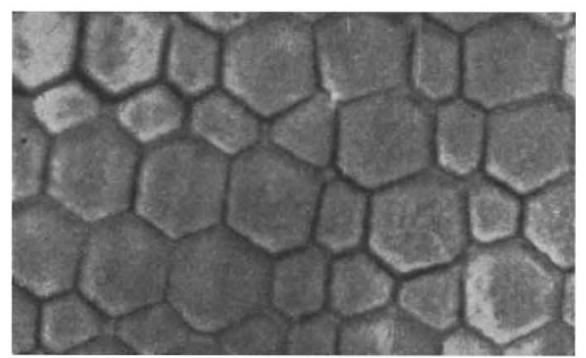

Fig. 1. Facetal part of the compound eyc of Leptidea amurensis

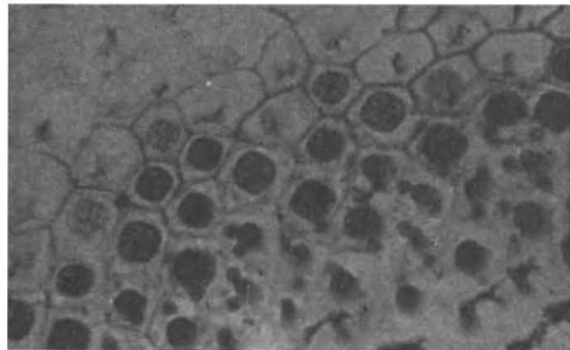

Fig. 2. Cross-section of a part of the corneagen cells with their irregular boundaries

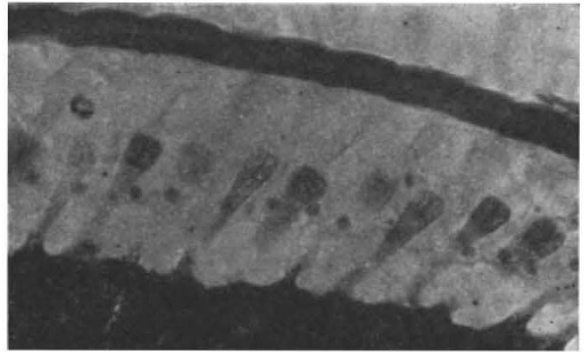

Fig. 3. Longitudinal section of the corneal part showing different corneagen cells present example. If we take into consideration the visual function of such an irregularly faceted compound eye, it is better to adopt our new juxta-position image theory ${ }^{2}$ rather than use Müller's mosaic vision theory ${ }^{2}$, which was proposed in $\mathbf{1 8 2 6}$ and is still found in almost all tho text books of biology and entomology.

Institute of Biology and Entomology,

Tokyo University of Agriculture, Tokyo.

${ }^{1}$ Yagi, N., and Koyama, N., The Compound Eye of Lepidoptera: Approach from Organic Evolution (Maruzen Co., Tokyo, 1963).

${ }^{2}$ Müller, J., Zur vergleichenden Physiologie des Gesichtsinnes der Menschen una der Tiere (Leipzig, 1826).

\section{VIROLOGY}

\section{Yellows Viruses in Sugar Beet and Mangold Seed Crops}

Proof of rapid spread of yellows viruses (BYV and BMYV) in sugar beet crops by wingless Myzus persicae ${ }^{1}$. coupled with evidence of large populations of this aphid on sugar beet and mangold seed crops ${ }^{2}$, led to the suggestion that if plants in these seed crops were infective while still symptomless the control measures used in the seed crops since $1950^{3}$, which have reduced heavy visible inspection in these crops to much lower levels ${ }^{4}$, may, nevertheless, not have impaired their efficiency as sources of these diseases for the root crop ${ }^{1}$.

Laboratory experiments have since shown that sugar beet plants became infective within 3 days (BYV) or 5 days (BMYV) after infected aphids commenced to feed on them.

Groups of 5 wingless aphids taken from plants with BYV were placed on 25 plants in a healthy seed crop on June 7, 1963; three days later these plants, and all neighbouring ones, were sprayed with 'Metasystox'. When the plants were scored 31,36 and 49 days after June 7, only 7,13 and 23 of them, respectively, showed any symptoms of infection. In a parallel experiment with BMYV, 4, 7 and 18 plants showed symptoms on the same dates. In the exceptional conditions of this summer, the rest of this seod crop appeared healthy.

Thus, with either virus, plants became infective within 5 days, but revealed symptoms, on average, only about 36 days after infection; this work supports the hypothesis that existing seed crop disease control measures are ineffective-which would explain why their introduction has not produced any decline in the incidence of yellows diseases in the root crop ${ }^{5}$. Other control measures have been suggested ${ }^{5}$.

School of Agriculture,

C. R. Ribbands Cambridge.

${ }^{1}$ Ribbands, C. R., Nature 197, 624 (1963); Bull. Ent. Res., 54, 267 (1963).

2 Kerslaw, w. J. S., Plant Path. (in the press).

${ }^{3}$ Hull, R., J. Roy. Agric. Soc., 113, 86 (1952).

4 Hull, R., Brit. Sugar Beet Rev., 31, 125 (1963)

${ }^{\circ}$ Ribbsnds, C. R., Nature, 195, 1230 (1962); Bull. Ent. Res., 54, Part 4 (1963)

\section{AGRICULTURE}

\section{Formation of Serotonin in Chopped Green Maize}

IN recont years several publications have appeared about amines in green forage plants. Fowler reported the presence of histamine in clover ${ }^{1}$, and $I$ reported an. increase of tyramino content in clover incubated under sterile conditions ${ }^{2}$.

Fresh green maize and chopped maize, which was taken from a trailer about $3 \mathrm{~h}$ after chopping, and also this same chopped maize 9 days after ensiling, were assayed for their amine content and the results compared (Table I). 